\title{
Modeling the Process of School Shooters Radicalization (Russian Case)
}

\author{
Anna Karpova ${ }^{1, *(\mathbb{D}}$, Aleksei Savelev ${ }^{2, *}$ and Nataliya Maksimova ${ }^{3}$ \\ 1 Division for Social Sciences and Humanities, School of Core Engineering Education, \\ National Research Tomsk Polytechnic University, 634050 Tomsk, Russia \\ 2 Division for Information Technology, School of Computer Science \& Robotics, \\ National Research Tomsk Polytechnic University, 634050 Tomsk, Russia \\ 3 School of Engineering Entrepreneurship, National Research Tomsk Polytechnic University, \\ 634050 Tomsk, Russia; nata8720@tpu.ru \\ * Correspondence: belts@tpu.ru (A.K.); sava@tpu.ru (A.S.)
}

Citation: Karpova, Anna, Aleksei Savelev, and Nataliya Maksimova. 2021. Modeling the Process of School Shooters Radicalization (Russian Case). Social Sciences 10: 477. https://doi.org/10.3390/ socsci10120477

Academic Editors: Christian Kaunert, Sarah Leonard and Thomas McNulty

Received: 15 October 2021

Accepted: 9 December 2021

Published: 13 December 2021

Publisher's Note: MDPI stays neutral with regard to jurisdictional claims in published maps and institutional affiliations.

Copyright: (c) 2021 by the authors. Licensee MDPI, Basel, Switzerland. This article is an open access article distributed under the terms and conditions of the Creative Commons Attribution (CC BY) license (https:// creativecommons.org/licenses/by/ $4.0 /)$.

\begin{abstract}
Research on radicalization became relevant to the study of terrorism and violent extremism just two decades ago. The accumulated empirical data on terrorism have led researchers and experts to understand that radicalization is a predictor of violent actions by terrorists, violent extremists, and lone actors. Violent incidents committed by school shooters are not terrorist crimes, but there is good reasons for inclusion as terrorist crimes since they have similar mechanisms. The article aims to create a conceptual model of school-shooter radicalization and determine the distinguishing features of the process. The paper presents a theoretical and methodological base of content analysis concepts, political models, and terrorist radicalization on the different levels of study. Based on the content analysis results, we identify the significant gaps in the research field, consider the radicalization phenomenon in detail, substantiated the qualitative aspects of the school shooters radicalization, and propose a conceptual scheme. Psychological, behavioral, cognitive aspects of the school shooters radicalization reflect a holistic picture of the relationship between the process phases and changes in the parameters of the object's state. The aspects of radicalization and this phenomenon's qualitative properties are interpreted as the determinants of the conceptual model. The model includes five stages, each of which is considered to be one of the components for the formation and acceptance of the idea of a violent way to solve a problem, but certainly do not act individually as the only component that leads to the actual implementation of the incident of a school shooting. An in-depth study of online social connections and warning signs, mobilization factors, behavioral trajectories, and imitation mechanisms can help scientists understand why school shooters are increasingly motivated to use violent means to achieve personal goals. We have outlined the possibilities and prospects of the model's application and directions for future research.
\end{abstract}

Keywords: youth; radicalization; extremism; terrorism; school shooting; school shooter; copycat criminal; conceptual models

\section{Introduction}

The school shooting phenomenon is a serious and growing threat around the world. Columbine high school massacre (one of the earliest incidents of school shootings, happened on 20 April 1999) has been called the deadliest spurt in the history of the mass murder and a 'cultural script' for many imitators. This massive wave of imitations has swept through various countries and has been termed the 'Columbine effect'. However, the first incident of school shooting in Russia was recorded only in 2014. Since then, the number of cases (both in Russia and worldwide) has increased, making the understanding of this phenomenon crucial for mitigation and prevention of future incidents.

Current academic discourse shows no consensus, not just on the roots of school shooting, but even on its exact definition. School shooting is differentiated from other acts of 
mass violence, based on the similarities shared by school shooting incidents. School shooters are motivated by a personal problem, by individualized search for glory and purpose through an act of mass violence. At the same time, school shooting shares characteristics of terrorism and violent extremism, such as planned ritualistic-demonstrative character of the act that serves a purpose of gaining recognition and following. We thus can adapt analytical models developed in studies of terrorism and extremism to advance our understanding of school shooting.

One of the main predictors for the violent actions in terrorism and extremism is the process of radicalization (LaFree 2013). Radicalization is generally defined as the process of transition from non-radical actions (i.e., non-violent forms of expressing opinions, ideas, behaviors) to radical actions (i.e., the violent forms). The key aspect of this transition is the acceptance of violence as the main means to achieve political, religious, ideological, or even personal goals. Radicalization is frequently used in studies of terrorism; however, it is rarely used in studies of school shooting. In the context of mass school murders, it is often difficult to determine when an incident is an act of terrorism and when it is a school shooting. In many countries, incidents of school shooting are simply categorized as mass murder, and we are not aware of any cases in which special legal acts have been applied. In the current Russian legislation and the legislation of other countries, there is no particular rule establishing criminal liability for this type of crime. There is no general law enforcement practice in the courts. School shooting incidents do not belong to crimes of a terroristic nature. Still, there exist good reasons for the inclusion of school shootings as terrorism since they have similar mechanisms and require strengthening law-enforcement practice concerning perpetrators of this type of crime.

The main goal of this paper is to formulate the conceptual model for the radicalization of school shooters. To fulfil this goal, we start by exploring the state-of-the-art of the current research to identify theoretical grounds for conceptualizing the phenomenon of school shooting. We summarize the available knowledge in studies of radicalization. We answer the question of whether the process of radicalization can be used as a predictor of school shooting. In this part of the paper, we also focused on approaches, methods, and tools for studying online radicalization. In the second part, we present the results of a content analysis of models of political, terrorist, and lone-actor radicalization. We highlight significant gaps in the models, identify key components of radicalization, and identify important aspects for constructing a conceptual model of school shooting and defining the properties of the process. In the third part, we describe the design of our study. In the fourth part we derive the model that we term the "School Shooter Radicalization Model" (SSRM). To derive the model, we applied an instrumental approach using qualitative attributes of the studied phenomenon as a basis for the development of the process' stages. It allowed us to create a holistic picture of structurally interconnected relations between process phases and changes in variable parameters of an object's state. In this part of the work, we describe the distinctive features of each phase, and the modus of the process. In the conclusions to this part of the work, we set forth our theses and support for the linear nature of the process of radicalization of school shooters, as well as the possibility of applying the SSRM model. In the conclusion, we outline the prospects for further research directions and possibilities for a research strategy to create tools to study the online radicalization of school shooters.

\section{State-of-the-Art}

Research on radicalization became relevant at the beginning of this century in the study of terrorism. One influential expert in the field, Garry LaFree, cites radicalization research as the third most significant achievement in empirical research on terrorism, expanding our knowledge of terrorism based on specialized datasets of specific subgroups of terrorism cases (LaFree 2013). At the beginning of the first decade of the 21st century, an expert community believed it was impossible to create a universal profile of a terrorist, extremist, and a mass murderer (this category includes school shooters). Additionally, 
it is this problem that has led researchers to search for a predictor of terrorism, violent extremism and crimes committed by lone actors.

The early research emphasized that the predictor of participation in violent activity was radicalization and that its study was critical. Over time, two opposing approaches emerged in the research field: a relativistic approach (which denies the idea that radicalization causes terrorism) ${ }^{1}$ and a contextual or meta approach (radicalization must be studied in the broad context of violent incidents beyond the study of violent extremist radicalization and terrorism) (McCauley and Moskalenko 2008; Neumann 2013; Onnerfors and Steiner 2018). Although criticisms periodically awaken academic researchers, they no longer generate a lively polemic around studies of radicalization.

Micro, meso and macro level studies of radicalization have developed over the last 20 years. Conceptually, they have three focuses: (1) the analysis of behavioral and sociopsychological attributes of radicalization, (2) analysis of the modus operandi of radical ideas, (3) and a meta-analysis, in which the process of radicalization should be viewed as a set of behavioral, psychological, social, ideological, mobilizational and other aspects of study. We will now look deeper into the development of ideas in the studies of radicalization.

\subsection{Studies of Radicalization}

Conceptual foundations for understanding the psychology of violent extremists and terrorists were established in 2004 by an expert in forensic psychology and terrorism, Randy Borum, and further developed by John Horgan (Horgan 2005, 2008, 2014) and Max Taylor (Taylor and Horgan 2006; Taylor et al. 2015). These researchers focused on the psychological mechanisms of radicalization. The central thesis they put forward is that radicalization and participation in terrorism is a gradual, step-by-step process that cannot be explained through an appeal to theories about the psychopathological state (Borum 2004, 2012; Horgan 2014). Specific psychological mechanisms are identified by other researchers in this field. For example, Arie Kruglanski emphasizes that the search for purpose and meaning in life is decisive in the individual process of radicalization (Kruglanski et al. 2013; Kruglanski 2009).

Randy Borum emphasized that social-action theory helps to identify the critical differences at all stages of the radicalization process, both from the motivation to commitment of radical acts and from the level of participation to the management of the process. Professor Anja Dalgaard-Nielsen emphasized the problem of collecting data on perpetrators' motives, which, in her view, is necessary for a solid empirical basis (Dalgaard-Nielsen 2010). According to Borum, Moscovici's theory of conversion is integral to the concept of radicalization. It links the study of conditions, situational factors, causes, personal motivational factors, cognitive mechanisms contributing to the transition to violent action and other components, thereby providing a platform for radicalization research. However, none of the currently available theories in the social sciences provides a complete explanation of the radicalization phenomenon (Borum 2011). According to researchers, there is no single pathway to radicalization, nor is there a single profile for a person who adopts the idea that a violent way of achieving a goal is the only possible way to solve a problem (Hofmann 2018). We are convinced that the most promising approach in this line of research is the socio-cognitive approach. In this approach, "radicalization [is] identified by a progressive and continuous transformation of representations, goals, beliefs and sources of reinforcement" (Garcet 2021, pp. 2-3).

The foundations for studying the modus operandi of the process of transition from radical ideas to radical actions, in cases of violent extremism and terrorism, were laid by psychologists Clark McCauley and Sophia Moskalenko. They outlined twelve mechanisms of political radicalization on three levels of analysis: individual, group and mass (McCauley and Moskalenko 2008). Based on nearly a decade of research, Clark McCauley and Sophia Moskalenko presented a unique two-pyramid model of political radicalization, which has become a benchmark for researchers in the field of terrorism and violent extremism. 
It is important to note that radicalization mechanisms differ in people depending on socio-demographic characteristics (Bokhari et al. 2006).

Subsequently, a new field of research emerged that focusses on risk factors for radicalization at the micro-, macro- and meso-levels (Borum 2011; Neumann 2013; Sarma 2017). The putative risk factors for radicalization began to acquire particular importance-these are the factors that can be confirmed by empirical studies and have been proven to play a role in radicalization (Kraemer et al. 2001). The researchers divide another group that determines the causative factors of radicalization into macro-level factors and meso-level. The macro-level includes external factors that determine functional, statistical, stochastic and other forms of determination of violent extremism and terrorism (Kerodal et al. 2016). The meso-level factors are determined by differences in political, socio-economic and cultural contexts, and vary significantly between countries ${ }^{2}$.

In the direction of meta-analysis of the study of the radicalization process, we can identify a multilevel approach. The multilevel approach aims to comprehensively assess radicalization risks, identify the correlation between micro-, macro- and meso-level variables; create a network cluster structure model to identify attributes (organizational hierarchy, network cohesion, ideological platform, etc.); predict behavioral trajectories, and identify geospatial, temporal components and more. The best example of a research service is PIRUS (Profiles of Individual Radicalization in the United States 1948-2018) This is an open service that allows scholars around the world to study profiles of individual radicalization across multiple variables, but unfortunately, only contains information from the United States. According to the researchers who developed the multilevel approach, radicalization depends on the context in which it occurs, and the violent content that social-media users consume (Rieger et al. 2020). Radicalization becomes widespread, viral and scalable as a result of the use of new communication technologies, but the Internet is not the cause of radicalization, but rather a tool that allows users of social media to become radicalized in a short time, on individual, group, and mass levels (Kirby 2007; Thompson 2011). The multilevel approach is not yet widespread, both because of its methodological complexity, and because of the lack of available, reliable and effective research tools and services, without which the collection, processing and analysis of big data in the online environment is challenging. However, it certainly opens new avenues for the studies of radicalization and can help to separate online radicalization studies into an important sub-field.

\subsection{Online Radicalization}

Radicalization in the online environment exhibits many attributes that are important in the transition from radical ideas to radical actions, such as situational, ideological, personal, motivational, mobilization and others (Breiger et al. 2011; Lara-Cabrera et al. 2017). Online radicalization is generally understood as a stochastic process that entails a person's involvement in an extremist, terrorist belief systems through online interactions that prepares the ground for violent acts offline. In the digital environment, the process of radicalization presents new features such as viral character, inclusiveness, and omnipresence. Over the past decade, the use of social media to disseminate and promote terrorist and violent extremist ideologies among users has increased dramatically. This resulted in the emergence of a whole new spectrum of studies focused on online radicalization.

The technologies for promoting radical ideas in social media by extremist and terrorist communities are rapidly evolving and effectively adapting to the ever-changing possibilities of the online environment, making it a difficult area of study for researchers. Artificial intelligence (AI) and Web Mining tools have been extensively employed for comprehensive assessments and operational analyses of risks and threats by automating the most time-consuming processes (Wendelberg 2021). Of great importance is the field of social media analytics, an interdisciplinary research area aimed at combining, extending, and adapting social media analysis methods for purposes in the subject area of study (Sureka and Agarwal 2014; Xie et al. 2016; Conway 2017; Gilani et al. 2017; Stieglitz et al. 2018). 
In all data mining tasks (including data transformation, feature reduction, algorithm selection, post-processing, and data interpretation) a priori knowledge is a pressing need. This leads to the need for representing the available knowledge in the form of ontological models that can be processed and formalized by machines. Creating models from the domain knowledge and transforming this knowledge into an ontology necessitates a formal description of the concepts in the domain, together with their properties and relationships, interpreting them as ontology classes and, at the same time, as parts of the ontological concept, called the knowledge base. The effectiveness of tools created, based on ontologies of the domain, directly depends on how accurately the indicators of radicalization are configured. An accurate classification ensures the calculation of indicators and leads to more accurate predictions of radicalization risks (Grimm et al. 2011; Lara-Cabrera et al. 2017).

The subject domain ontologies that define the basic concepts of radicalization are referred to as low-level concepts. Subject matter ontologies that relate to radicalization indicators or indicators under consideration are referred to as high-level concepts. For example, the concept of terrorist radicalization was used in the creation of the ontology of terrorism as part of the low-level ontology "Terrorist-Personality" (Turner 2011). Having analyzed the current state of research in the field of creating automated systems, relying on subject domain ontologies, we state that over the past decade in the field of radicalization research several promising works have appeared in which subject domain ontology is used to conduct an intelligent analysis of social-network data. For example, the Ontological Framework to Facilitate Early Detection of 'Radicalization' (OFEDR) is based on the application of a semantic approach to the search for indicators of radicalization in social networks, and includes low-level and high-level ontologies (Wendelberg 2021).

\subsection{Studies of School Shooting}

The focus of school-shooting studies is largely the same as of the studies of radicalization. For example, the analysis of behavioral and psychological attributes (causes, conditions, personality traits) or the focus aimed at the study of ideological and semantic foundations and motives of violent behavior (Larkin 2009; Weatherby et al. 2010; Rocque 2012; Séguin et al. 2013; McCauley and Moskalenko 2014). A separate research area aimed at studying the typology of imitation, which is critically important, because the similarity between mechanisms of school-shooter imitation and the syndrome of imitative suicides was substantiated in the earliest publications, and the study of this topic has not lost its relevance (Kostinsky et al. 2001; Towers et al. 2015; Hofmann 2018). It is important to emphasize that suicidal thoughts, according to experts, are rarely the only or main motive in committing school shooting acts. Suicidal thoughts are more often found in combination with other motives and are secondary to them. This is supported by results of numerous studies (Towers et al. 2015), and highlighted in the 2019 reports of the National Threat Assessment Center (NTAC, USA) ${ }^{3}$ and ALERRT Center (USA) ${ }^{4}$. Several studies attempt to follow and assess the degree of influence that social media has on the growth of imitating incidents (Malkki 2014; Meindl and Ivy 2017). The current understanding suggests that widespread media coverage of a school shooting incident and the subsequent social media resonance promotes interest in the perpetrator and increases the likelihood of imitative follow-up acts. Some researchers, based on a study of school shooting incidents in the United States, state that the 'copycat effect' persists for an average of two weeks (Towers et al. 2015).

A meta-analysis aimed at studying the school shooting phenomenon as a set of psychological, behavioral, socio-psychological, and sociocultural factors has also been actively developed (Kimmel and Mahler 2003). A systemic view of the school shooting phenomenon was proposed in as early as 2004, and was substantiated in a comprehensive theory of school shooting. This theory is based on five factors, although the researchers themselves claim that these factors are not exhaustive and require further empirical testing and additions (Newman et al. 2004; Newman and Fox 2009). One relevant example of a 
meta-analysis is the work of Langman, who proposed the first typology of school shooters. He also compiled a school shooters database ${ }^{5}$ and developed a research approach based on combining biological, psychological and social patterns (Langman 2017). Throughout Langman's studies, he emphasizes the basic idea that "there is no one cause of school shootings, despite efforts to pin the blame on a single cause" (Langman 2017, p. 27). Thus, school shooting requires a meta-level approach.

The importance of studying the online environment, online communications, and content is noted by most researchers, but specialized software, such as the ones developed for the study of terrorism, is not yet available. It is possible to use prototypes developed for studies of terrorism and violent extremism, but they require significant adaptation, improvement, development of ontologies of the subject area, and further contributions to the knowledge base. Some researchers use existing prototypes, adapting them to the objectives of the subject area such as Dr. Langman, who has assembled a knowledge base of warning signs for school shooters (Langman 2021). We doubt that it is possible to build such a collection in a manual search mode, but we have not found a description of the tool.

\subsection{Similarity Markers}

To summarize the current state-of-the-art in studies of radicalization and school shooting, we highlight markers that support the idea that there are many similarities between terrorism and violent extremism and school shootings. Violent extremism is seen as "encouraging, justifying or supporting the acts of violence to achieve a political, ideological, religious, social or economic goal" (Borum 2011, p. 8). In understanding terrorism, we rely on the academic consensus definition of terrorism offered by Alex Schmid as a "calculated, demonstrative, direct violent action without legal or moral restraints, targeting mainly civilians and non-combatants, performed for its propagandistic and psychological effects on various audiences and conflict parties" (Schmid 2011, pp. 39-40).

Let us highlight the first marker with the following key attributes: demonstrative nature with direct violent actions without legal or moral restrictions and the purpose of propagandistic and psychological influence on various audiences. These attributes reflect the essence of school shootings, as well as the essence of terrorism. The ritualistic and demonstrative nature of school shootings, in which the shooter "tries on" the role of a god, is identical to the same characteristic manifestations in the actions of terrorists and violent extremists. The psychological impact, both on the victims themselves and on a wider audience, through an act of intimidation, is typical of both school shooters and terrorists. The intent of the school shooters is to make a statement, to leave a message for a wider audience, and it is similar to the statements and manifestos of lone-wolf terrorists. Self-preservation is not a goal, nor it is a goal for suicide bombers. In fact, in both cases, dying in an incident is a way to exit life as a "revered hero", to "honorably" finish the job.

The second marker is that the school shooters see committing a violent act as the preferred means to achieve a goal, which coincides with the actions of terrorists and violent extremists. This is a planned form of violence. Additionally, for both, there is no individual target, what matters is the number of victims. This indicates the symbolic nature of violence. In addition, the motive and the choice of targets are related. However, unlike traditional terrorist groups, which have political, religious, or ideological goals, school shooters see their goal as solving their personal problems based on personal motives, i.e., the search for fame, personal revenge, recognition among peers, overcoming a crisis or unstable life situation, despair, feelings of hopelessness, and even sometimes suicide. If we interpret terrorism as ideologically motivated, planned violence, then a school shooting can be interpreted as problem-motivated planned violence.

The third marker is cultural. A cultural determinant in the actions of terrorists and school shooters is that violence is perceived as one of the main ways to gain recognition and respect. The possession of weapons and the ability to commit violence is attributed to the man, and is seen as proof of one's own masculinity, importance, and ability to influence others. 
The fourth marker is group identification. The group identification is a significant component of the radicalization of terrorists and violent extremists. Group identification is accompanied by a stable identification with a specific movement, organization or community and has a pronounced ideology. Regarding school shooters, the idea of group identity is also significant because they identify themselves with their predecessors, not as individuals (as, for example, in cases of mass murderers), but as a symbolic community in which they draw a source of inspiration and examples to follow, providing themselves with a sense of belonging to a conventional community of people who have achieved success. The criterion of success for school shooters is the completion of an idea, its public resonance, fame, and the trace left in the public consciousness. It is no coincidence that hybrid types are often found in the typology of imitation, i.e., when the school shooters imitate or are inspired by several figures simultaneously, thus identifying with the symbolic community. A hybrid form of identification occurs when a school shooter identifies with movements, radical communities (e.g., neo-Nazis) whose beliefs they share, or specific heroic figures (e.g., Hitler) and adherence to one or more heroic school shooter figures.

Some researchers have used the term radicalization in their studies of school shooting or have labeled the process of engaging in school-shooter ideas as radicalization, but the term itself has not been implemented in the context of school shooting (Böckler et al. 2013; Oksanen et al. 2014). We see many commonalities between terrorists and school shooters in behavioral, socio-psychological, cognitive, and other attributes in the transition from a radical idea to violent action. The body of theoretical knowledge and empirical evidence in the study of radicalization, as well as the contextual approach that we follow in interpreting the phenomenon of radicalization itself, allows us to consider the process of radicalization as a predictor of school shooting incidents.

\section{Models of Radicalization}

In this section, we examine the accumulated experience of modeling terrorist radicalization, political radicalization, and lone-actor radicalization as a basis for constructing a conceptual model of school shooter radicalization. The Borum's model is an example of an attempt to identify universal components of radicalization. This four-step model describes radicalization as a linear process (Borum 2004). The process begins with pre-radicalization, whereby a person or a group recognizes an event as wrong for them. The next step is the recognition of the event as unfair. Next, attributing blame for the event to an individual or a group and acknowledging their responsibility for the alleged injustice. The final step is creating an image of an enemy in the 'other(s)'.

The idea of a linear process of radicalization was further developed by Moghaddam (Moghaddam 2005), who formulated a 'ladder' model of radicalization. First, a person feels injustice and relative deprivation. Then, a person becomes more angry and looks for the culprit of injustice, creating an image of an external enemy, ready to release the accumulated aggression. Next, a person begins to justify terrorism and shows moral adherence to terrorist convictions. After this, there is a "red line" of demarcation: the person joins a terrorist group. The person makes a step towards justifying violent actions as the only possible way to solve the problem of injustice. The person starts dehumanizing enemies to legitimize violent actions. Finally, the person commits a terrorist act. A new conceptual extension in the Moghaddam's model is an understanding of the process of individual and group radicalization as a complex phenomenon, in which many factors including internal and personal causes, and external conditions play a role.

Further building on these ideas, Taylor and Horgan focused their attention on psychological problems of entering and exiting terrorism (Taylor and Horgan 2006). Terrorist radicalization, as a gradual, stepwise process starts with (1) the predetermining event that is augmented with (2) personal factors that emerge in the (3) social, political, and (or) organizational context. According to the authors, this approach facilitates a better conceptual development of the analysis of the psychology of terrorists and the development of more practical and effective counter-terrorism initiatives. 
The conceptual model of political radicalization, developed by psychologists Clark McCauley and Sophia Moskalenko, provided a significant theoretical contribution to understanding the process of radicalization, allowing a new perspective on this process. The authors theoretically substantiated twelve mechanisms of radicalization at three levels of study, namely, individual, group, and mass levels. Each, according to the authors, requires particular attention and the development of conceptual models. The process of radicalization depends on the influence of both external and internal factors. The common basis for 10 out of the 12 mechanisms of radicalization is that they have a reactive quality and appear in the context of group identification and reaction to perceived threats to the group. The reactive radicalization mechanism stems mainly from the dynamics of intergroup conflict. The common basis for the two remaining mechanisms is that they are autonomous and associated with the manifestation of variability and distortions in individual psychology. The variety and strength of the mechanisms that manifest themselves in different ways at the individual, group, and mass level indicate the need to understand and a functional separation of the radicalization process (McCauley and Moskalenko 2008). The dichotomy of the radicalization process is presented by the authors through functional separation (McCauley and Moskalenko 2008). The idea was developed and conceptually framed in the two pyramids model, in which the authors present the process of radicalization as a transition from radical ideas and expression of opinions to extreme actions in the form of a pyramidal ladder (McCauley and Moskalenko 2017).

In proposing the idea that radicalization is not a linear process, but rather a cycli$\mathrm{cal} /$ staged one, the authors substantiate the thesis that there is no direct connection between radical beliefs and radical actions; accordingly, one cannot view the former as a predictor of the transition to the latter, to the commission of violent actions. We have no doubts about this approach in studying political radicalization, and we use the two-pyramid model as a basis for studying the political radicalization of the far-rights in Russia (Karpova et al. 2020; Kuznetsov et al. 2021). However, in cases of school shootings, we observe a different, linear picture, and believe that radical ideas and opinions, are formed by school shooter at the stage of motivation. We are convinced that, when applied to the study of school shooters' radicalization, it is the linear nature of the process that captures the essence of the shooter's "ascent" from the stressor to the idea of solving a personal problem through violence. Thus, to create our model, we accounted for the differences in the mechanisms of linear radicalization, and laid down the tasks of creating markers for low-level ontology, using personality factors as the basis.

Since school shooters are placed in the category of lone actors, we turned to research on the radicalization of lone-actor terrorists and mass murderers. The conceptual model of lone-actor terrorist radicalization by Mark Hamm and Ramon Spaaij has become the basis for studies of lone-actor terrorism worldwide and serves as a theoretical complement to other studies of lone-actor terrorism in the United States and Europe (Feve and Bjornsgaard 2016; Gill 2015; Silber and Bhatt 2007). Based on an analysis of 98 cases of lone-wolf terrorism in the U.S. from 1940 to 2013, the authors describe the following six stages of the process: (1) personal or political reason for discontent, (2) affinity with sympathizers or an extremist group, (3) activation (stimulus), (4) translation of intent, (5) initiating event, (6) terrorism (Hamm and Spaaij 2015).

In our work, we considered an important component identified by the authors in the radicalization of lone-actor terrorists, that is, the broadcasting of the intent and the initiating event. We already noted in the State-of-the-art section that school shooters leave many warning signs, broadcasting intent to a wider audience. This is one of the markers in the mobilization phase of our model. A triggering event, such as the experienced social stress, gradually builds up the cumulative effect of personality transformation. Such an event is a reactive factor, but also, in a situation of social stress, a potential abuser with self-regulation skills has a way out, an adaptation to the situation. The transformation of the school shooter's personality is characterized by a progressive aggravation, which includes a change in behavior, a change in social connections, a social hermitage. Moreover, 
school shooting is not caused by random and sudden "mental insanity", so a consideration of the psychopathological version of school shooting is not productive, and does not provide a reliable basis for an explanatory framework. The psychopathology of school shooters has its place, and it practical ways to identify this type of school shooter should certainly be considered, studied, and searched for. However, many researchers of lone-actor radicalization and school shooters, conclude that the crimes studied are rarely related to psychopathology, although most had pronounced psychological problems. For example, they experienced depression and despair (Spaaij 2010; Ferguson et al. 2011; McCauley and Moskalenko 2014).

Peter Langman, based on the results of a comparative study of 48 cases of school shooting and 55 cases of mass murders committed by lone actors, identified and systematized different types of influences, imitation, and inspiration, and presented evidence of overlap between the role behaviors of mass murderers and school shooters (Langman 2018). Typologies of influence include heroic idealization, godlike worship, personal resemblance, and reckless passion. The typology of imitation identifies the following markers: quick imitation, imitation as honoring, imitation as pilgrimage and imitation as copying (speech, appearance, behavior). The typology of inspiration contains such markers as general inspiration, sympathy to the motive and fulfillment of another's will. When conducting a study of Russian school shooters and developing a model, we used the proposed typology as the basis and identified markers of influence, imitation, and inspiration.

In recent years, there has been an active discussion in the research field about the "loners," who were once nicknamed "lone wolf" in publicity. Academic scholars have been critical of the incorrect "diagnosis" and, accordingly, provide a critical analysis of the inappropriate typology (Schuurman et al. 2019). According to Kaplan, Lööw, and Malkki, "the lone vigilante motif has appeared in every era and in virtually every culture in the world" (Kaplan et al. 2014, p. 1). The social hermitage of the lone actor, for quite a long time in the research field, was considered as a modus operandi, which negated the possibility of identifying and preventing incidents. Until recently, the hypothesis of the social hermitism of loners seemed obvious. Researchers believed that lone incidents are the most difficult to prevent because these individuals have no contact with groups or other radicalized individuals. Therefore, their actions are entirely isolated, and, accordingly, there are fewer opportunities for information leakage and more opportunity to maintain operational security. However, studies of the social connections of loners in the online environment refuted this hypothesis. In this context, we should note the conceptual model of David Hofmann (Hofmann 2018). He summarized evidence from case studies by Hamm and Spaaij (200 cases), Gill, Horgan, and Deckert (119 cases), Schuurman, Bakker, Gill and Bouhana (55 cases) (Feldman 2013; Gill et al. 2013, 2016, 2017; Hamm and Spaaij 2017; Schuurman et al. 2017). The author's key conclusion is that the broader socio-political environment and the relationships that lone terrorists form in the online environment influence their motives, methods, and ideology.

In addition, David Hofmann developed a conceptual model of the social connections of lone-wolf terrorists in an online environment by summarizing empirical data on two significant cases of lone terrorists from the Global Terrorism Database (GTD) and the Canadian Incident Database (CIDB). Focusing on the study of behavioral, operational, and social aspects, he highlighted the following four types of social connections: (1) a wide network, (2) an ideological network, (3) a signaling network and (4) a support network (Hofmann 2018). This model became the basis for research on the online radicalization of lone actors.

Empirical data accumulated on school shooting incidents in the United States has allowed scholars to conduct an in-depth analysis and conclude that perpetrators act alone with respect to the actual perpetration of an incident. They may be in a social vacuum in the real world, but it is exactly the degree of external influence and social connections in the online environment that are crucial, and sometimes critical, throughout the radicalization process (Hofmann 2018). We considered the importance of identifying social connections 
in the online environment when conducting research on Russian school shooters. In the Materials and Methods section, we describe the results of the study. For our model, we used David Hofmann's typology of social connections.

Summarizing the analysis of radicalization models, we note that the creation of universal profiles leads to dead-end and purely speculative concepts that focus only on the psychological aspects of radicalization, downplaying attention to the analysis of sociologically grounded explanations, i.e., causal factors at the macro, meso and micro levels. It is obvious that groups use social media to radicalize neophytes, so studying online radicalization becomes critically important. However, if it is achievable at the level of studying group radicalization, to determine the degree of the formation of radical beliefs by topical content, adherence to certain ideological, political, terrorist, extremist views, social ties, online organization and some other markers, the task will become quite approachable. At the very least, the possibilities become expanded with the use of prototypes for the intelligent analysis of social-media data. However, in the study of loner radicalization in the online environment, the possibilities are much less clear. The online radicalization of school shooters is also extremely poorly studied, although since Columbine, the decisive role of the Internet in the contagion of school shooter ideas has not been questioned.

In fact, these findings take us back to the idea expressed by Bakker and de Graaf (2011) that "loners are by definition idiosyncratic, they display a diverse background with a wide range of ideologies and motivations, hardly their history betrays anything in terms of patterns or repeated methods behind the attack ... it is particularly difficult to distinguish those who actually intend to carry out attacks from those who merely express radical beliefs or empty threats (hoaxes)" (Bakker and de Graaf 2011, p. 46). Given all the above, we note that the problem with conceptualizing a phenomenon as difficult as radicalization is the challenging nature of determining where the process of radicalization begins, and from what point a person should be considered as an active part of this process. Our analysis of the current state of radicalization research suggests that the concepts and models developed in terrorism studies can be applied in the context of the study of school shooting, and will significantly expand our knowledge and understanding of this phenomenon.

\section{Materials and Methods}

We conducted a case-study to better understand the school shooting phenomenon in Russia. In this study, we had the following objectives: to identify types of imitation, significant correlations, to analyze the dynamics of cases, to collect statistics by gender and age, type of institution, type of weapon, and to study social connections in the online environment. As a result, a database was compiled that includes publicly available data on cases of school shootings in Russia committed by young people of various age groups. The study covers the period from the very first documented incident in 2014 to a recent incident in September 2021. In this case study, we analyze incidents that occurred and incidents that have been prevented.

There is no particular norm for establishing criminal liability with regard to this type of crime in current Russian legislation. There is no general law enforcement practice in the courts. Thus far, courts have prosecuted under the following articles of the Criminal Code of the Russian Federation (Criminal Code of the Russian Federation 2008): Part 2 of Article 105 (murder), Article 205 (act of terrorism), Part 4 of Article 206 (hostage-taking), Part 3 of Article 30 (preparation for a crime and attempted crime), Part 2 of Article 116 (beating), Article 222 (illegal acquisition, transfer, sale, storage, transportation, transfer or carrying of weapons, main parts of firearms, ammunition), Article 317 (encroachment on the life of a law enforcement officer), Part 2 of Article 115 (intentional infliction of light injury to health), Article 213 (hooliganism), Article 35 (commission of a crime by a group of persons, a group of persons by prior conspiracy, an organized group or a criminal association_criminal organization), Part 1 of Article 223.1 (illegal manufacturing of explosives, illegal manufacturing, alteration or repair of explosive devices), Article 282 (incitement of hatred or enmity, as well as humiliation of human dignity). As one can see, 
there is an absence of special terminology related to school shootings, that could be used as the basis for developing special legislative norms. The introduction of legal terminology into circulation is urgent, since it will prepare the legal basis for a special normative-legal act to overcome legal conflicts, an understanding of this kind of crime and accordingly adequate legal assessment of the public danger of both the criminal act itself and the person who committed it. This is critically important not only for Russia, but also for other countries.

To the best of our knowledge, there is also no single definition of school shooting in academia. For the purpose of this case study, we define school shooting as the planning, organization, and execution of an armed attack inside or on the premises of an educational institution (of any level) by one or more students, carried out through public and demonstrative acts of violence, with the intent of mass murder. The perpetrator is motivated by one idea or one problem rather than a broad ideology, the intent is often unspecific, the use of violence is seen as justified and as the only possible means of achieving the goal. School shooting must be viewed as a stochastic phenomenon in which the occurrence of a violent act can be statistically predictable, but individual perpetrators are difficult to predict.

Our compiled database of incidents is based on information from open sources, including the official website of the Investigative Committee of the Russian Federation (IC RF), publications in the media, Internet sites, information in communities of the social network VK, archives of regional and federal electronic newspapers, foreign sources of information in the media, etc. An additional data source is the School Shooters database (see Note 5). In most cases, several sources were available, describing cases in which researchers and journalists used different data, which were often contradictory, so a list of incomplete reports was also compiled.

To create the database we started with an automated search through the open information from the crime reports from the Ministry of Internal Affairs of Russia (MVD). The crimes were first filtered to only include the crimes committed by youths (defined as 14-35 years old according to Russian legislature). The acquired dataset was further filtered to only include the crimes for which persons were prosecuted under the articles of attempted terrorism, extremism, and mass murder. This narrowed the search from 600-1300 cases of terrorism, extremism, and mass murder per year to a set of 115 cases that we considered as potential school shooting incidents. The selected cases were cross referenced with the databases of the National Antiterrorist Center (NAC) and the National Center for Information Counteraction to Terrorism and Extremism (NCPTI). To further refine the incidents that can be categorized as school shooting, we included only the incidents on the premises of educational establishments of any level. This resulted in 34 selected cases. We further removed the cases that had very limited information available to public (this were usually prevented cases). So, the final list contained only cases that had records in the IC RF and MVD, and that were also covered by official media sources (such as TASS, Interfax, etc.). By cross references multiple sources, we were able to both verify and refine the available information. The vetting resulted in the sample of 21 cases. Through this pre-processing step in the creation of our model, we were able to collect important statistics for further analysis. This included attributes provided in Table 1. 
Table 1. Key attributes collected after the automatic search through the open crime reports.

\begin{tabular}{|c|c|c|c|c|}
\hline ID & $\begin{array}{l}\text { Age at the Time of } \\
\text { Incident }\end{array}$ & Date of the Incident & Place of the Incident & $\begin{array}{l}\text { Type of Educational } \\
\text { Establishment }\end{array}$ \\
\hline Type of weapon & Number of dead & Number of injured & Hostages taken? & Suicide attempted? \\
\hline $\begin{array}{l}\text { Taken into } \\
\text { custody? }\end{array}$ & Primary motive & Secondary motive & $\begin{array}{l}\text { Was in the police registry } \\
\text { before the attack? }\end{array}$ & $\begin{array}{l}\text { Psychological } \\
\text { evaluation }\end{array}$ \\
\hline $\begin{array}{l}\text { Articles of } \\
\text { prosecution }\end{array}$ & $\begin{array}{l}\text { Available media } \\
\text { sources }\end{array}$ & $\begin{array}{c}\text { Online statements } \\
\text { before/during the } \\
\text { attack? }\end{array}$ & $\begin{array}{c}\text { Registered on social } \\
\text { networks? }\end{array}$ & $\begin{array}{c}\text { Additional } \\
\text { uncategorized facts }\end{array}$ \\
\hline
\end{tabular}

Identified cases were further studied for activities in the online environment. Information from the Internet was collected via an API on the open data of topical communities, accounts of the social network VK using a module of a software algorithm developed by our team. No personal data, or data allowing us to identify the users who interacted with the school shooter or whether they were members of the same topical community, were collected. The software module includes several functions created to automatically search, process and analyze large social network data. The module (Vilnin et al. 2021) was originally developed to study far-right communities in Russia and was tested in pilot studies of different cases. It is used as a tool for social and political science research on the process of online radicalization of youth in social networks, which was designed as part of a multifunctional software (Karpova et al. 2019; Savelev et al. 2021). One of the features used in the school shooting study was based on a new method of calendar-correlation analysis (CCA). The method includes a mathematical model for identifying the target group by the characteristic change in group activity in the vicinity of key events and a knowledge base (for example increased activity near the date of Columbine massacre incident). For the purposes of the study, the module was used to identify target communities, thematic agendas, and social connections in the online environment. The principal scheme of the module's algorithm is available in Appendix B.

Our compiled database contains 25 variables in the following categories: statistical data, motive, typology of imitation, law enforcement, social connections, warning signs/variants of their use by the perpetrators, and more. The results of the study were published in February 2021 (Karpova and Maksimova 2021). We used the following approaches: case study, content analysis and web mining.

We found that there is no unified profile of the school shooter, and there is no specific (recognizable by characteristic features) profile of the institution that was targeted, nor is there a significance of the location (see Figure 1). The perpetrators differed in age (see Figure 2), social characteristics, grade and type of education (paid/free), and in the combination of motives. It was observed that only 4 of the 21 offenders were found to be insane, and only 1 was on the police register. The dynamics of incidents are characterized by a non-linear dependence and the analysis of incidents reveals no significant dependence on the month or year. The suggestion (which is often popular in the media) that most of the school shooters plan and carry out their attacks on Columbine's anniversary does not stand up to empirical test. The types of weapon used or recovered in a planned incident are shown in Figure 3. Quantitative data beyond 21 incidents means that the perpetrator used/planned to use more than one type of weapon. For example: a firearm and explosive device, or a bladed weapon and an explosive device. We have explored the typology of imitation. There were 3 cases that were imitating the Kerch shooter (incident at the Kerch Polytechnic College on 17 October 2018, Russia). The Columbine incident (Columbine High School incident on 20 April 1999, USA) was imitated in 14 cases. And 1 case was influenced by ideology of NBK (Natural Born Killers, a reference to the film of Oliver Stone is the generalized name of communities on the social network VK, in which the life stories of serial killers, school shooters, mass murderers and high-profile incidents of school shooting are promoted, replicated, discussed, and described ${ }^{6}$ ). Finally 2 cases 
were influenced by the ideology of neo-Nazism. We also found that most school shooters had one motive, related to solving one problem. However, in at least 5 cases out of 21 an additional explanation contributed to the decision to attack. Examples of the main reason include revenge for humiliation, revenge for bullying, seeking fame/significance, bullying, peer ridicule, ostracism, and others. Examples of an additional motive are rude/offensive congratulations on social networks, personal dislike, psychological crisis.

\section{Distribution by type of institution}

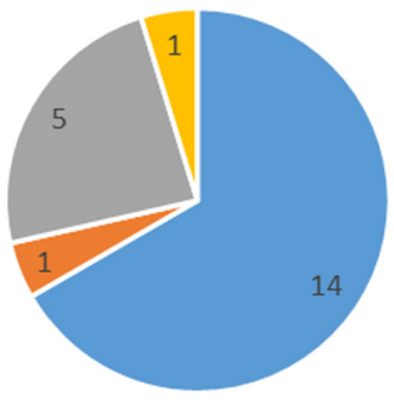

$$
\begin{array}{ll}
\text { - Secondary school } & \text { - Private educational institution } \\
\text { = Technical school, college } & =\text { Univercity }
\end{array}
$$

Figure 1. Distributions by type of institution ( $\mathrm{N}=21$ cases).

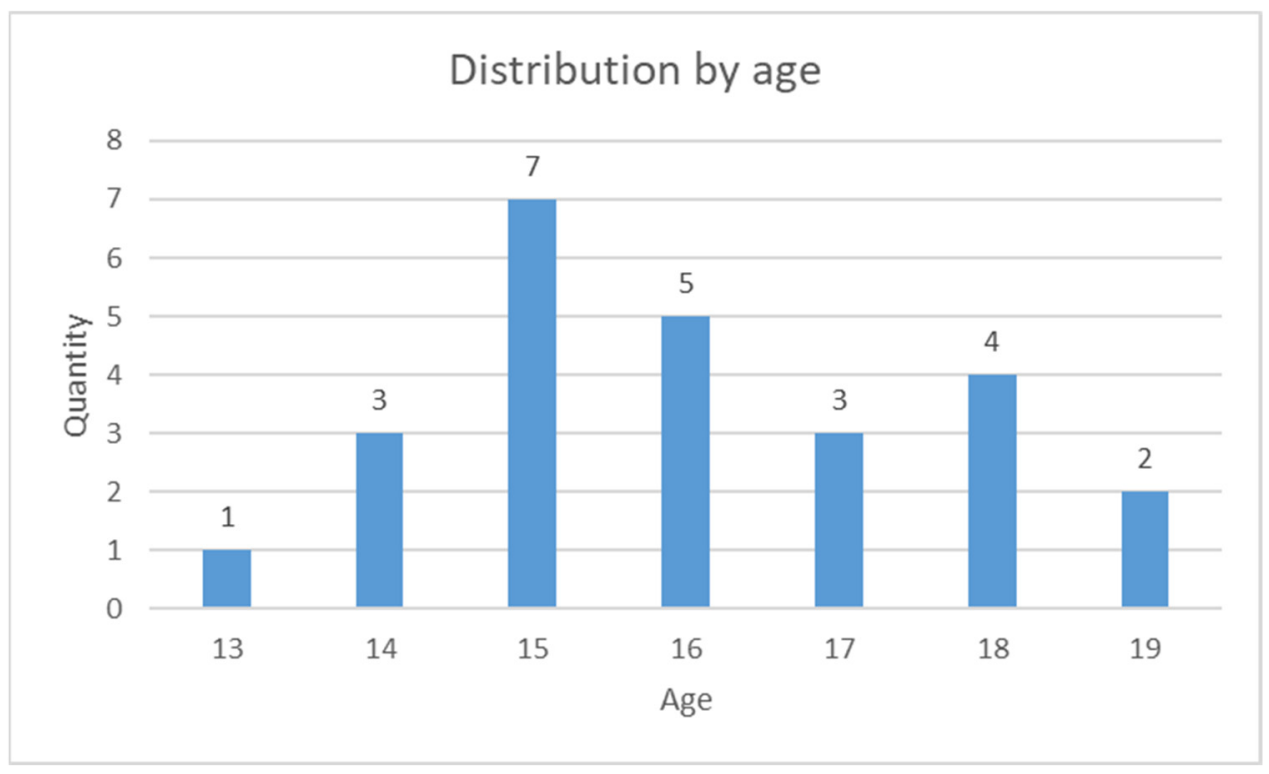

Figure 2. Distribution by age $(\mathrm{N}=21$ cases $)$. 


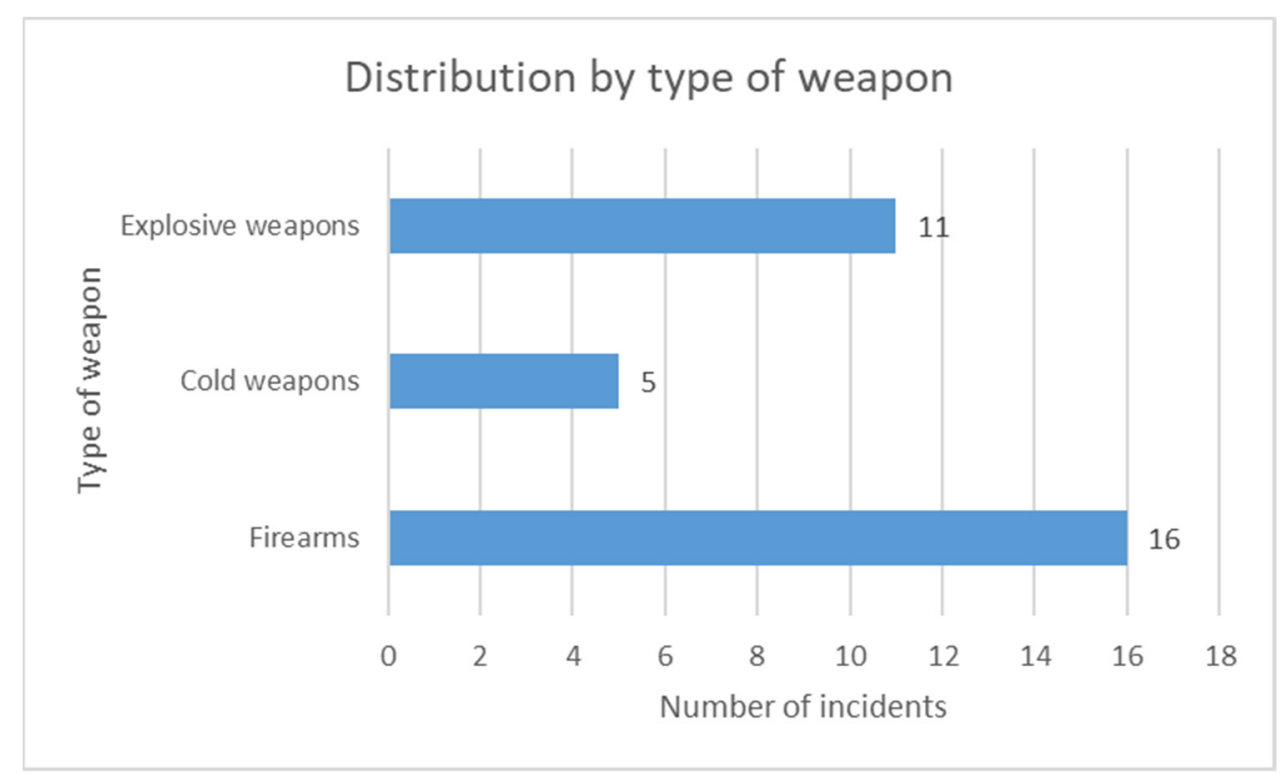

Figure 3. Distributions by type of weapon $(\mathrm{N}=21$ cases). Cold weapons are non-fire arms (knifes, blades, etc.) ${ }^{7}$.

A characteristic confirmation of media-influence in Russia is the replication of destructive practices of school shooters through a detailed description of the organization, planning, and motives of the perpetrator, indicating specific "triggers" in the form of the name of social networking communities. By doing so, the media provides potential imitators with information and knowledge of gaps in the attack scenario. For example, the massive, detailed coverage of the incident committed by the Kerch shooter, in the city of Kerch in 2018, generated a wave of imitators and a heroization of the criminal; it provided imitators with relevant information about significant oversights in his scenario, problems with preparing explosive devices and obtaining weapons permits.

In four cases, two types of imitation influence a school shooter, namely, the ideology of neo-Nazism and extremist communities PWL (in Russian "AYE") ${ }^{8}$. In another case, inspiration from the Kerch shooter and the doctrine of Nazism were found to be types of imitation influencers. One shooter followed three imitation types: Kerch shooter, neoNazism, death squad Russian National Unity (RNU) ${ }^{9}$. RNU is a generalized name of VK communities, which promote, replicate, discuss suicidal views, ways and ideas to leave life "with style" and with meaning. In the Appendix A to the article we include a complete chart of the cases of the types of influence for imitation.

School shooters used several accounts on the social network Vkontakte with different nicknames, which were a direct reference to Columbine or other heroized events. Warning signs were present in status, location designations, comments, posts, or symbols on the wall. For example, a school shooter who committed an incident in May 2019, has, as his status the phrase: "HATE + WRATH + KILLER = NATURAL SELECTION. City: Roslyakovo". Another warning sign in the Vkontakte status directly referenced the "Death Squad" ideology, a status that was left by the perpetrator of the incident in September 2017. He wrote the phrase "delete my life 09/05/17".

In all of the 21 cases selected, the attacker left either an SMS or posted a message on social media. Several people sent a message to a specific person via messenger/SMS. Most left a message to a broader audience (classmates, members of the social network community) posted on a video hosting platform. In 3 cases, criminals used 2-4 channels of information transmission, including video message, a manifesto in social networks, message in Telegram channel and audio recording. In 3 cases, the attackers kept a personal diary, recording information about the planned attack. Although a small number of users (from 20 to 1000 people) subscribed to the attackers' accounts, the attackers themselves 
subscribed to broader communities (from 5 to 20 Vkontakte-communities). Concerning the intention to act, some of the attackers posted messages on the Internet in which they directly or indirectly expressed their desire to "kill someone." In several cases, they openly declared their threats towards people or property.

Examples of statements, quotes from manifestos, messages found on the pages of wannabes in the social network VK:

"Tomorrow you will be surprised what I will do";

"Don't go to school, there will be meat";

"My life is a game, and no one knows when it will end ... or maybe it will be interrupted...";

"No one is born evil. It's what you learn";

"I'm in school, and I'm scared. Very scared, but it must be done. No matter what anybody thinks of me, no matter how it will turn out. I must. That's it, good luck everyone, I hope Dmitri survives, he's my friend. I hope it all goes well";

"The reason for everything is DISAPPOINTMENT. Just as I am a disappointment to people, people are a disappointment to me. I guess that's all I wanted to say. Goodbye, everybody";

"I'm not scared. We'll just disappear later. Slam, and that's it,"

"Hell will start on 22 near home. Zhyza [loosely translates as 'that's life']. Ahahahaha."

There are several common topics that attackers most often discuss, namely, weapons, bullying, violence, revenge, depression, suicide or self-harm, issues related to deprivation and existential issues. In each of the 21 school shooting cases, the attacker experienced at least one social-stress factor. Many have experienced stressors in other aspects of their lives (study, conflict with a teacher, conflict with peers, family, etc.).

Summarizing the case of school shooting in Russia, we conclude that the pattern of incidents is similar to such events taking place all over the world, with school shooters following a common scenario. However, we found several distinctive features. First, it is not spontaneous, but a planned, purposeful violence, unlike cases in other countries, where both accidental and purposeful attacks occur. Second, the "copycat syndrome" becomes a key factor for Russian school shooters. Third, a hybrid subculture has formed in the Russian social network VK, combining the cult of American and Russian school shooters. Fourth, online radicalization with a cumulative effect becomes an important milestone in the planning and execution of attacks.

\section{School Shooter Radicalization Model}

The problem of modeling school shooter radicalization is in the choice of inclusion criteria that are appropriate to the process. On the one hand, our goal was to propose a conceptual model in which the source provides the qualitative aspects of the study of the radicalization process underlying the various mentioned approaches, namely the psychological, behavioral and cognitive aspects of the study. On the other hand, it was important for us to distinguish the phases of the process based on the empirical results of the study. We applied an instrumental approach to process modeling, which allowed us to create a holistic picture of structurally interconnected relations between individual elements (process phases) and changes in state variables (object properties). Although linear models of terrorist radicalization have previously been discredited, we believe that it is the linear nature of the radicalization process that reflects the essence of the psychological, behavioral, and cognitive changes of a school shooter in the context of the transition from the idea of solving a personal problem to committing an act of violence. Next, we provide a brief description of the qualitative aspects and key properties of the process itself. 


\subsection{Psychological}

The motivation of school shooters has similarities to other cases of targeted violence (mass murder, terrorism), where in the first stage of radicalization, the critical ingredient is discontent. However, unlike group radicalization, school shooters' discontent is personal and combines personal problems, individual circumstances, personal perceptions of those circumstances, and of the experiences. The shooter is motivated by one problem or idea, not a broad ideology. Most had one main motive related to solving one problem. For example, revenge for humiliation/bullying, search for fame/significance, bullying, etc. The additional motive is more personalised, occurs less often, and acts as a secondary motivating factor. For example, a conflict with a teacher, rude/insulting birthday or holiday wish on social networks, resentment against a specific person, etc.

The social isolation of school shooters in the offline environment is more voluntary than forced. However, because most school shooters are supported or actively use social connections in the online environment, school shooters cannot be characterised by total social solitude. Additionally, these social connections were found to be integral to their motivation, mobilization, and incident preparation.

\subsection{Behavioral}

We studied how behavioral manifestations affect the development of an individual trajectory of planning, preparing, and committing an act of violence. Distinctive markers are: (1) Identification with a role model, (2) Identification with a heroic persona; (3) Growing perseveration; (3) Inspiration by the personified success; (4) Direct copying.

A distinctive feature of group radicalization is its pronounced ideological orientation. Ideology is paramount, not the person who embodies this ideology. However, for school shooters, on the contrary, personality as the embodiment of personified success is of decisive motivation. Specific heroized characters, who have achieved perceived success, become a source of inspiration and role models. The success criterion is the person's fame and the trace (public attention) left in the public consciousness. One of the main factors that provoke incidents of imitation among school shooters is extensive, detailed media coverage of the event.

\subsection{Cognitive}

This aspect indicates that the school shooter becomes more and more in entrenched in the formation of the belief that only a violent way is justified and that it is the only possible means for solving the problem. It manifests itself through the following factors:

1. The person experiences a highly intense emotional perception of a personal problem and attitude towards life in general.

2. The person feels a mental state of frustration and the experience of negative emotions (for example, a feeling of relative deprivation, alienation/social isolation, disdain and a sense of insecurity).

3. Introversion (focus on internal mental activity).

The cognitive aspect is a social and psychological process, gradually experienced adherence (gravitation) to the idea of violence, which is characterized primarily by the emergence of the illusion of a quick solution to the problem.

\subsection{Process Properties}

The radicalization of school shooters is characterized by linearity, but the stochastic nature is characteristic of radicalizations' development and escalation. Random factors play a significant role in changing the direction and intensity of radicalization. School shooters have no obvious offline connections through which they can be discovered. They do not communicate much about themselves and their intentions to their surroundings in the offline environment. However, at the same time, they leave many warning signs in the online environment. They stick to their plans and, at a certain point in time, step out of the shadow and commit an act of violence. School shooting should be regarded as a 
stochastic phenomenon, whereby attackers are statistically predictable but individually challenging to predict. The process of radicalization and acceptance of the idea of school shootings is characterized by contradictions, uncertainty, and spontaneity rather than ideologically solid beliefs, attitudes, and commitments. We are convinced that stochasticity as a property of the process of radicalization of Russian school shooters is important and needs to be further studied. Due to a complex set of cause-and-effect relationships, this process depends on the specific context in which it unfolds. Therefore, each case of a school shooting requires a separate, detailed analysis. Our current understanding of the Russian case is that each school shooter evaluates their own situation and forms the basis of motivation based on their preferences for choosing markers of personalized success, subsequently integrating them into a personal motivation system. It is no coincidence that we noted in the Materials and Methods that, in the Russian case study, we identified five cases of hybrid forms of imitation and influence (see Appendix A).

The school shooter radicalization model consists of the following five phases: (1) predictor-social stress, (2) motivational stage, (3) mobilization stage, (4) terminal stage, (5) incident (see Figure 4).

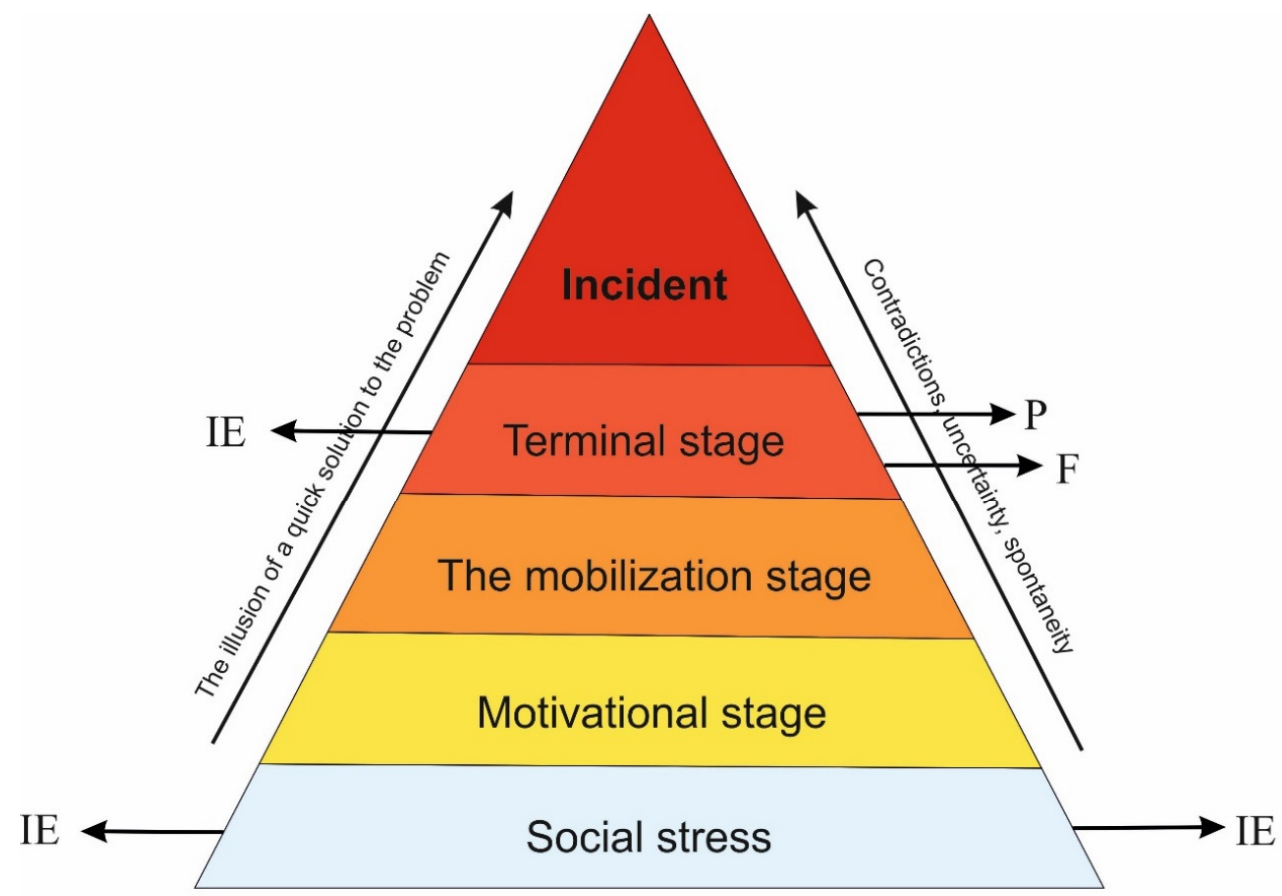

Figure 4. Conceptual model of radicalization of school shooters. IE-Independent Exit. P-Prevention. F-Fading.

\subsection{Social Stress as a Predictor}

According to Peter Langman, the hallmarks of school shooters are a complex web of personality traits, family history, social influences, identity problems, and sometimes mental illness (Langman 2009, 2015). Any social stress can lead to the formation of motives for committing violent acts, however the majority of people do not commit mass violence. According to Peter Langman, a combination of biological, psychological, and social patterns contributes to mass violence, but vary by age and in combination with other problems (Langman 2017, pp. 27-28).

Social pressure can be caused by the social environment and through specific problems in relationships with others. According to the cognitive theory of emotions, social stress occurs when a person interprets an event, a situation at the emotional level of cognitive assessments of others, someone else's behavior in terms of attitudes towards oneself, ones' needs, interests and values. We can identify the main categories of social stressors for school shooters. We define life events as abrupt and severe changes in life that require 
a person to adapt (for example, a change in school) quickly. Chronic stress is defined by ongoing events that require a person to adjust over a long period (for example, conflicts, humiliation). Daily troubles are minor events that require adjustment during the day (e.g., resentment, jealousy). When stress becomes chronic, an individual experiences emotional, behavioral, and physiological changes that lead to a clear motive for violent behavior. Since cognitive assessments determine the quality and strength of the experienced emotions, insofar as, in a situation of social stress, a potential attacker concludes that he does not have the resources to cope with a specific problem. Thus, he begins to search for a way out of the current, and, in his opinion, dead-end situation. In this phase, there is the possibility of a "free exit" from social stress. It depends on the conditions, psychological support, and the subject's ability to adapt.

Those who use the "free way out" are people who refuse to use violence as the solution. The reasons for this may be different, and may include fear, stricter legislation, acceptance of the "it's not worth it" conviction, etc. Suicide can also be a way out of a life crisis, from despair and hopelessness. External factors can lead to a change of goals or a complete abandonment of the plan. The influence of internal factors (subjective interpretation) can strengthen the process of transition to the act of committing violence. We must also consider the fact that a permanent relationship between internal and external factors determines the resulting action. However, in order to verify this hypothesis, additional research is necessary. At the current stage of research, it is still too early to definitively answer the question as to where that boundary lies, and the moment at which the decision of the school shooter to commit violence becomes irreversible.

\subsection{Motivational Stage}

Motivation is the first step to generate radical ideas. At this stage, there is a search for a way to solve the problem and a fulcrum. The formed motive gives rise to the desire to solve the problem in any way. The motivational stage is associated with the emergence of the decision that violence is the only possible way to solve the problem. It is characterized by a focus on the situation and by the prolonged accumulation of negative emotions, increasingly harsh expressions of opinion, angry/negative emotional assessments, and the search for justification of thoughts and plans. This stage is also characterized by the legitimation (recognition, approval, confirmation of significance) and the rationalization of actions to provide the "project" with a meaning and direction.

The importance of legitimation for school shooters lies in the fact that they are trying to find recognition of their importance in society (even in this criminal way), and justification for their actions. The ability to achieve fame through violence is not new, recall the story of Herostratus, who burned down the temple of Artemis in Ephesus in order to be remembered by posterity. The search for significance in incidents of school shooting is a key mechanism in the process of individual radicalization, determined by the extreme features of youth consciousness, i.e., the desire to make oneself known as widely as possible.

Furthermore, there is a process of identification with a role model, heroization of the perpetrators of incidents, and the study of their stories and an identification with the ideal model of personified success. We characterize the individual radicalization of school shooters through alienation, escapism, and consistent distance from society as a whole and any form of group relations. Key markers of the motivational stage are (1) concentration, (2) identification, (3) legitimation.

\subsection{Mobilization Stage}

It is impossible to achieve a goal by only thinking about an idea. The decisive actions are integral, at least actions as basic as looking for resources (money, weapons, support). The critical concept of mobilization is to move towards actual results. At this stage, social connections in the online environment become a vital component to support motivation, planning, resource seeking, and implementation. Through discussing topics in thematic communities that are significant for school shooters, the idea is supported and concretized 
(in Hofmann's classification). Topics that attackers most often discussed include weapons, bullying, violence, revenge, depression, suicide, existential issues. The choice of the target of the attack is also a debated topic. Most school shooters make statements on the Internet (social networks, messengers, image boards) about their intention to harm, and leave a lot of warning signs in the online environment (according to Hofmann). The purpose can be specific and explicit, or it can be vague and not clearly defined, but in both cases, there is intent. Intention also entails a concern for purpose. The key markers of the mobilization stage are (1) design, (2) object selection, (3) resource search, (4) plan.

\subsection{Terminal Stage}

The stochasticity of the process is especially pronounced at this stage. An attacker can perform a "free exit" from the process. A fading phase may begin, which will either end with an incident or remain only at the idea's formalization level. However, also, at this stage, significant opportunities arise for detecting, suppressing activities, and, in general, preventing an incident. They directly depend on the measures that the cybercriminals take to ensure the operational security of their "project".

In most school shooting cases, there is evident neglect of attackers in ensuring the secrecy of their plans, or their attempts are exceptionally ineffective. In addition, identifying warning signs in an online environment increases the chances of an incident being prevented. At the terminal stage, a unique role is played by the "initiating event", a symbolic internal threshold between the goal and the decision to launch an attack. Such an initiating event may be illness, expulsion, or, for example, an acute conflict. Peter Langman has divided all school shooters into targeted and accidental (Langman 2009) categories. The former experienced chronic, long-standing conflicts and showed significant warning signs of impending violence. It is this form of school shooter who can most often be stopped at the fading stage.

The accidental shooters had no long-term conflicts and showed fewer warning signs, but they were the deadliest. They are characterized by a sharp transition from the terminal stage to the incident. In cases of Russian school shooters, we found no examples of accidental shooters, either among the prevented or the committed incidents. The preventions of the attempts were the result of significant operative and investigative actions taken by law enforcement officers. The principle role in implementing the "initiating event" belongs to the media, which provokes the effect of imitation and incites more and more stochastic loners through the creation of the "Star image". The key markers of the terminal stage are (1) emotional perseveration, (2) initiating event, (3) imitation effect.

\subsection{Incident}

A dangerous trend that is causing concern worldwide is the visualization of the attack, associated with the unlimited use of digital technology to broadcast the incident. The gamification of the mass murder events is not new. Journalists dubbed this method "selfie jihad" (Burke 2016). Live broadcasts from the attack scene acts as an attractor for individuals across the globe and a universal hint for imitators.

\subsection{Outlook for the Model}

In the model, we sought to show the linear nature of the radicalization process, the connection to concepts in the subject area of the study and modelling of terrorist radicalization, highlighting and justifying the phases of the process, and outlining the qualitative aspects of the school shooter radicalization process. We aim to conduct further empirical research to test and expand this model so as to advance its conceptual foundation. We also offer the model as a basis for empirical case validation to researchers from other countries. We see the prospect of applying the model to the creation of a subject area ontology to study the radicalization of school shooters. The next step is to apply the presented model to create a high-level ontology. We are confident that formalizing the psychological, cognitive, and behavioral components will allow us to highlight indicators 
of online school shooter radicalization, on the basis of which we will create a dataset and extend the functions of the software prototype. We plan to test the prototype in the social network VK and the Telegram messenger.

\section{Conclusions}

The radicalization process of school shooters has many similarities with political and terrorist radicalization. We see common behavioral, psychological, and cognitive attributes of the transition from a radical idea to a violent act, which leads to the idea that the predictor of committing an incident of school shooting is the process of radicalization. The linear nature of the radicalization process reflected in the conceptual model demonstrates a step-by-step process of transformation of the school shooter from the idea of solving a personal problem to the commission of a violent act. The linear nature of the process seems to us to be essential because it allows us to understand how the school shooters are mobilized to commit an act of violence.

The radicalization of school shooters is rarely an isolated process. It takes different forms depending on the identification not with individuals, but with the symbolic community in which they draw inspiration and role models, providing themselves with a sense of "success", significance, and the ability to influence those around them. The criterion of success for the school shooters is the fulfillment of an idea, public resonance, fame, and the trace left in the public consciousness. They see the commission of a violent act as a means for achieving the goal, which is the same as the actions of terrorists and violent extremists.

It is a planned violence, perceived by perpetrators as one of the main ways to gain recognition and respect. However, unlike traditional terrorist groups, which have political, religious or ideological goals, the school shooters see their goal as solving their personal problems based on personal motives. The ritualistic and demonstrative nature of school shooting and the psychological impact through an act of intimidation, is typical of the same manifestations in the actions of terrorists and violent extremists.

Social relations in an online environment have a significant impact on the path of radicalization. School shooters are connected through virtual communities on the Internet, creating numerous network contacts. Despite acting in isolation, school shooters are not alone online, but they can be alone offline. Many researchers have suggested that the threat of lone-actor radicalization is no longer an exceptional case, but perhaps the "standard" for a new generation of perpetrators and can be seen as a future model for lone-actor terrorism. The Internet is a driving force for this type of criminal activity. Additionally, school shooters leave numerous warning signs on the internet. The school shooting incidents inspire imitators, cause many deaths, and pose the most serious threat, maybe a greater risk than group incidents due to more difficulties in preventing such cases.

Conceptualizing the process of radicalizing school shooters can establish new directions for future research. First of all, it focuses the attention of researchers to the study of mobilization factors of radicalization of school shooters. Second, studying background characteristics (conditions, environment, life cycle events, social connections) that can contribute to the formation of violent beliefs. Third, to gain further knowledge about the mechanisms of online radicalization of school shooters, it is necessary to use network topology tools to study the structure, dynamics and build a model of the relationships they form in the online environment. Fourth, special attention should be given to detecting warning signs that can help to identify the vulnerabilities of school shooters and thus to prevent incidents. Fifth, the stochastic nature of the process requires a deep study of the probabilistic characteristics of the initial data using the mathematical apparatus of the theory of probability and of random processes, which can help to better understand the phenomenon. Sixth, the creation of a subject-matter ontology will formalize qualitative attributes, highlight indicators of school shooter radicalization, develop a classification based on existing typologies, and further, software modules for the automatic search, processing and analysis of large amounts of social media data. Finally, working with such 
tools will produce results in a shorter time, and thus allow researchers to create predictive models to assess the risks of radicalization.

Author Contributions: Conceptualization, A.K.; methodology, A.K.; software, A.S.; validation, A.K., A.S. and N.M.; formal analysis, A.K., A.S. and N.M.; data curation, N.M.; writing-original draft preparation, A.K.; writing-review and editing, A.K. and A.S.; visualization, A.S. and N.M.; supervision, A.K.; project administration, A.K.; funding acquisition, A.K. All authors have read and agreed to the published version of the manuscript.

Funding: This research was funded by Ministry of Science and Higher Education of the Russian Federation as a part of the project No. FSWW 2020-0014.

Institutional Review Board Statement: Not applicable.

Informed Consent Statement: Not applicable.

Data Availability Statement: The data are available upon request from the corresponding authors.

Conflicts of Interest: The authors declare no conflict of interest.

\section{Appendix A}

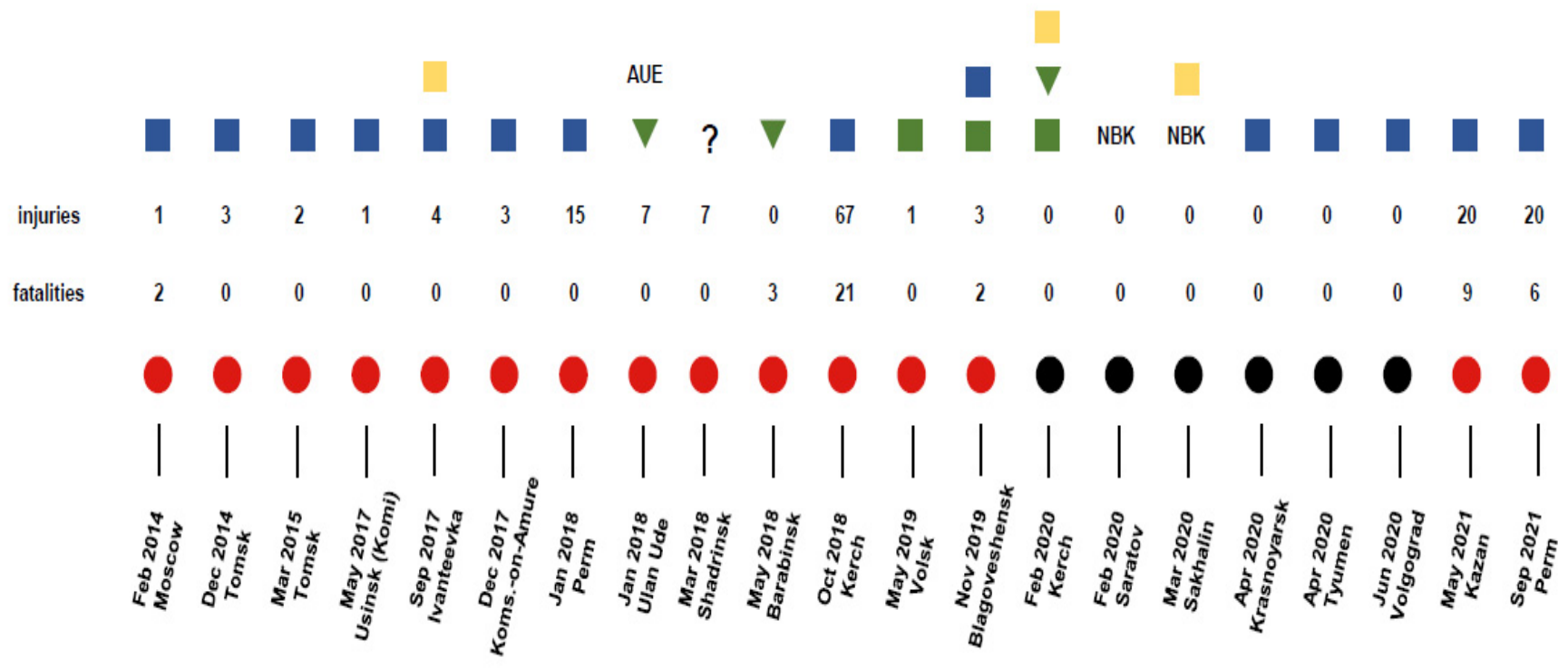

AUE Prisoner way of life

NBK Community VK "NBK"

Neo-Nazism
Community VK

Death Groups

Kerch shooter

Columbine

Figure A1. 21 cases of school shooting in Russia: general scheme. 


\section{Appendix B}

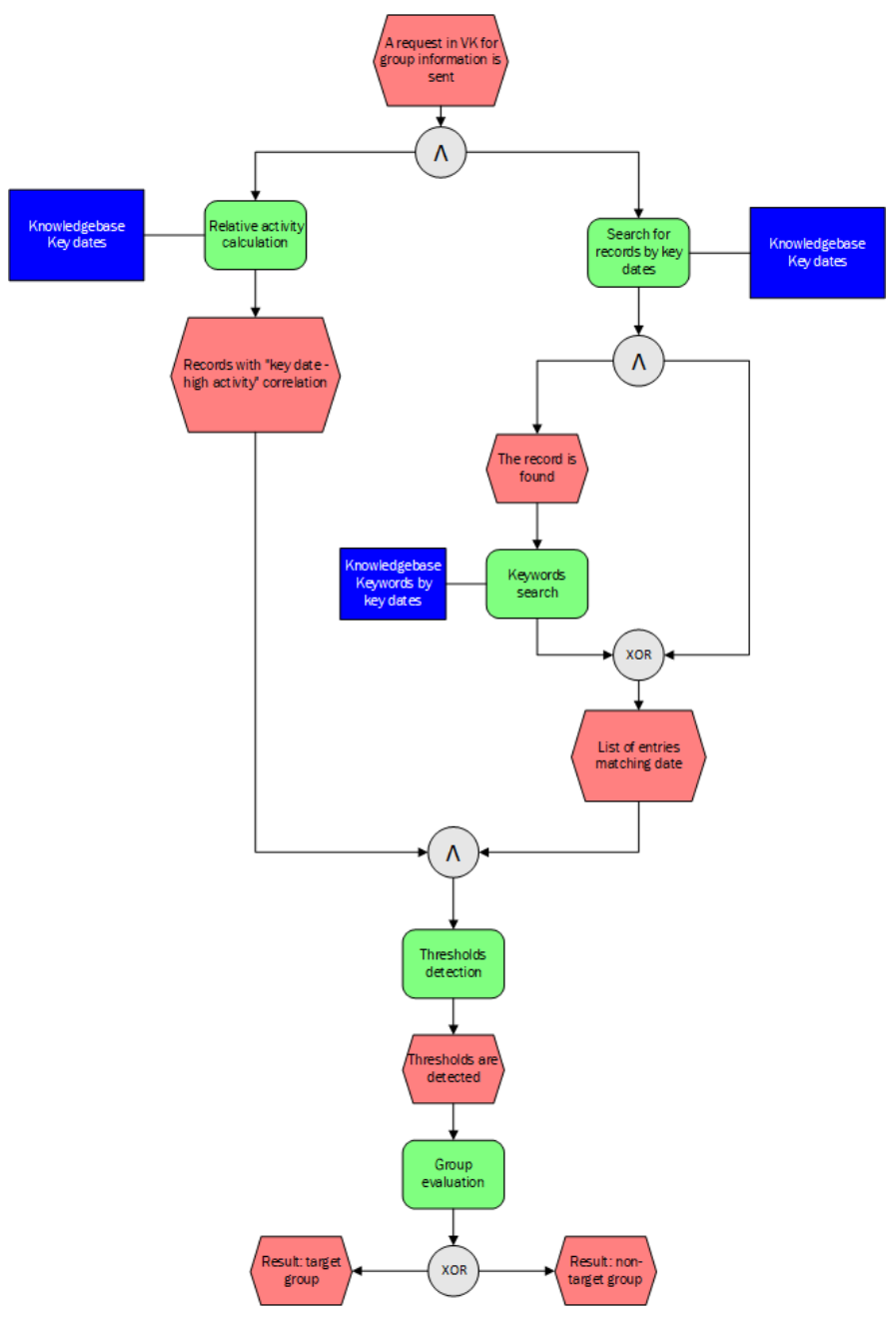

Figure A2. EPC diagram of the CCA algorithm.

\section{Notes}

1 See, for example, statements to the media, John Horgan: Director of the International Center for the Study of Terrorism at the University of Pennsylvania and forensic psychiatrist, former CIA officer Marc Sageman. Article by John Knefel (6 May 2013): Everything You've Been Told About Radicalization Is Wrong. Rolling Stone. URL: https://www.rollingstone.com/politics/ politics-news / everything-youve-been-told-about-radicalization-is-wrong-80445/ (accessed on 8 December 2021); Article by Mehdi Hasan (28 May 2013): Woolwich Attack: Overreacting To Extremism ‘Could Bring Back Al Qaeda' Ex CIA Officer Warns. Huffington Post. URL: https:/ / www.huffingtonpost.co.uk/2013/05/27/sageman-interview_n_3342206.html (accessed on 8 December 2021).

2 See for example: (Brockhoff et al. 2015; Dillon 2009).

3 Protecting America's Schools: A U.S. Secret Service Analysis of Targeted School Violence [Electronic resource]/L. Alathari. 2019. URL: https://schoolshooters.info/sites/default/files/Protecting-Americas-Schools.pdf (accessed on 8 December 2021).

4 Active Shooter Incidents in the United States in 2019 [Electronic resource]/U.S. Department of Justice Federal Bureau of Investigation. April 2020. URL: https:/ / schoolshooters.info/sites/default/files/active-shooter-incidents-in-the-us-2019.pdf (accessed on 8 December 2021).

5 (School Shooters n.d.) Electronic resource, URL: https://schoolshooters.info, free access (accessed on 8 December 2021).

6 VK communities, collectively labeled with the NBK tag, include a number of communities that use names other than Natural Born Killers such as Super Columbine Massacre, True Crime Community, Mafia Trench Coat, Columbine communities, etc. Moreover, the names of the communities are in English transcription with the Russian version provided (literal translation of the English version). 
7 In the Russian legislation, the Supreme Court defines the concept of a cold weapon-a weapon designed to hit the target with the muscular force of a person in direct contact with the object of destruction. According to the law, cold weapons include sabers, a checkers, knives, daggers, Finnish knives, dirks, brass knuckles, stilettoes and other objects, specially designed or adapted for striking a living target. Methods of attack include stabbing, stabbing-cutting, chopping, crushing, etc. URL: http://www.consultant.ru/document/cons_doc_LAW_12679/ (accessed on 8 December 2021). An assailants' choice of stabbing and cutting weapons is probably due to the inaccessibility of firearms.

$8 \quad$ PWL (prisoner way of life) is the name and motto of the criminal subculture of the Russian informal gang's association, consisting of underage adolescents.

9 RNU—Russian National Unity. Russian ultra-right nationalist, paramilitary organization.

\section{References}

Bakker, Edwin, and Beatrice de Graaf. 2011. Preventing lone wolf terrorism: Some CT approaches addressed. Perspectives on Terrorism 5: 43-50.

Bokhari, Laila, Tomas Hegghammer, Brynjar Lia, Peter Nesser, and Truls H. Tonnessen. 2006. Paths to Global Jihad: Radicalisation and Recruitment to Terror Networks. Paper presented at the FFI Seminar, Oslo, Norway, March 16.

Borum, Randy. 2004. Psychology of Terrorism; Tampa: University of South Florida. Available online: https://www.ojp.gov/sites/ g/files / xyckuh241/files / media / document/208552.pdf?height=921.6\&q=psychology-of-terrorism\%3FTB_iframe\%3Dtrue\& width=921.6 (accessed on 8 December 2021).

Borum, Randy. 2011. Radicalization into violent extremism I: A review of social science theories. Journal of Strategic Security 4: 7-36. [CrossRef]

Borum, Randy. 2012. Radicalization into Violent Extremism II: A Review of Conceptual Models and Empirical Research. Journal of Strategic Security 4: 37-62. [CrossRef]

Böckler, Nils, Thorsten Seeger, Peter Sitzer, and Wilhelm Heitmeyer. 2013. School shootings: Conceptual framework and international empirical trends. In School Shootings: International Research, Case Studies, and Concepts for Prevention. New York: Springer, pp. 1-24. [CrossRef]

Breiger, Ronald L., Gary A. Ackerman, Victor Asal, David Melamed, H. Brinton Milward, R. Karl Rethemeyer, and Eric Schoon. 2011. Application of a Profile Similarity Methodology for Identifying Terrorist Groups That Use or Pursue CBRN Weapons. Berlin/Heidelberg: Springer. Available online: https:/ /link.springer.com/chapter/10.1007/978-3-642-19656-0_5 (accessed on 8 December 2021). [CrossRef]

Brockhoff, Sarah, Tim Krieger, and Daniel Meierrieks. 2015. Great expectations and hard times: The (nontrivial) impact of education on domestic terrorism. Journal of Conflict Resolution 59: 1186-215.

Burke, Jason. 2016. The Age of Selfie Jihad: How Evolving Media Technology is Changing Terrorism. CTC Sentinel 9: 16-22.

Conway, Maura. 2017. Determining the Role of the Internet in Violent Extremism and Terrorism: Six Suggestions for Progressing Research. Studies in Conflict \& Terrorism 40: 77-98. [CrossRef]

Criminal Code of the Russian Federation. 2008. Parallel Russian and English Texts. Moscow: Center JurInfoR Ltd.

Dalgaard-Nielsen, Anja. 2010. Violent radicalization in Europe: What we know and what we do not know. Studies in Conflict $\mathcal{E}$ Terrorism 33: 797-814.

Dillon, Michael R. 2009. Wahhabism: Is it a Factor in the Spread of Global Terrorism? Master's Thesis, Naval Postgraduate School, Monterey, CA, USA. Available online: http:/ / citeseerx.ist.psu.edu/viewdoc/download?doi=10.1.1.386.7829\&rep=rep1\&type= pdf (accessed on 8 December 2021).

Feldman, Matthew. 2013. Comparative Lone Wolf Terrorism: Towards a Heuristic Definition. Democracy and Security 9: 270-86. [CrossRef]

Ferguson, Christopher, Mark Coulson, and Jane Barnett. 2011. Psychological Profiles of School Shooters: Positive Directions and One Big Wrong Turn. Journal of Police Crisis Negotiations 11: 141-58. [CrossRef]

Feve, Sebastien, and Kelsey Bjornsgaard. 2016. Lone-Actor Terrorism: Database Workshop. Available online: https://rusi.org/exploreour-research/publications/occasional-papers/lone-actor-terrorism-database-workshop (accessed on 8 December 2021).

Garcet, Serge. 2021. Understanding the psychological aspects of the radicalization process: A sociocognitive approach. Forensic Sciences Research 6: 115-23. [CrossRef]

Gilani, Zafar, Ekaterina Kochmar, and Jon Crowcroft. 2017. Classification of Twitter Accounts into Automated Agents and Human Users. Paper present at the International Conference on Advances in Social Networks Analysis and Mining, Sydney, Australia, July 31-August 3; pp. 489-96. [CrossRef]

Gill, Paul. 2015. Lone-Actor Terrorists: A Behavioural Analysis. London: Routledge.

Gill, Paul, John Horgan, and Paige Deckert. 2013. Bombing Alone: Tracing the Motivations and Antecedents of Lone-Actor Terrorists. Journal of Forensic Sciences 59: 425-35. [CrossRef]

Gill, Paul, John Horgan, Emily Corner, and James Silver. 2016. Indicators of Lone Actor Violent Events: The Problems of Low Base Rates and Long Observational Periods. Journal of Threat Assessment and Management 3: 165-73. [CrossRef] 
Gill, Paul, James Silver, John Horgan, and Emily Corner. 2017. Shooting Alone: The Pre-Attack Experiences and Behaviors of U.S. Solo Mass Murderers. Journal of Forensic Sciences 62: 710-14. Available online: https:// onlinelibrary.wiley.com/doi/full/10.1111/1556 -4029.13330 (accessed on 8 December 2021). [CrossRef]

Grimm, Stephan, Andreas Abecker, Johanna Völker, and Rudi Studer. 2011. Ontologies and the semantic web. In Handbook of Semantic Web Technologies. Berlin: Springer, pp. 507-79.

Hamm, Mark, and Ramon Spaaij. 2015. Lone Wolf Terrorism in America: Using Knowledge of Radicalization Pathways to Forge Prevention Strategies: Final Grant Report to NIJ. Available online: https://www.ojp.gov/pdffiles1/nij/grants/248691.pdf (accessed on 8 December 2021).

Hamm, Mark, and Ramon Spaaij. 2017. The Age of Lone-Wolf Terrorism. The Age of Lone-Wolf Terrorism. Studies in Transgression. New York: Columbia University Press. [CrossRef]

Hofmann, David C. 2018. How "Alone" are Lone-Actors? Exploring the Ideological, Signaling, and Support Networks of Lone-Actor Terrorists. Studies in Conflict E Terrorism 43: 657-78. [CrossRef]

Horgan, John. 2005. The Psychology of Terrorism. London: Routledge.

Horgan, John. 2008. From Profiles to Pathways and Roots to Routes: Perspectives from Psychology on Radicalization into Terrorism. The Annals of the American Academy of Political and Social Science 618: 80-94. [CrossRef]

Horgan, John. 2014. The Psychology of Terrorism, 2nd ed. New York: Routledge.

Kaplan, Jeffrey, Helene Lööw, and Leena Malkki. 2014. Introduction to the Special Issue on Lone Wolf and Autonomous Cell Terrorism. Terrorism and Political Violence 26: 1-12. [CrossRef]

Karpova, Anna Yu, and Nataliya Maksimova. 2021. Schoolshooting in Russia: What matters? Power 9: 93-108. (In Russian)

Karpova, Anna Yu, Aleksei O. Savelev, Alexandr D. Vilnin, and Denis V. Chaykovskiy. 2019. New technologies to identify alt-right extremist communities in social media. Vestnik Tomskogo Gosudarstvennogo Universiteta-Filosofiya-Sotsiologiya-Politologiya-Tomsk State University Journal of Philosophy Sociology and Political Science 52: 138-46. [CrossRef]

Karpova, Anna Yu, Aleksei O. Savelev, Alexandr D. Vilnin, and Denis V. Chaykovskiy. 2020. Studying Online Radicalization of Youth through Social Media (Interdisciplinary Approach). Monitoring of Public Opinion: Economic and Social Changes 3: 159-81. [CrossRef]

Kerodal, Ashmini, Joshua Freilich, and Steven Chermak. 2016. Commitment to Extremist Ideology: Using Factor Analysis to Move beyond Binary Measures of Extremism. Studies in Conflict \& Terrorism 39: 687-711. [CrossRef]

Kimmel, Michael, and Matthew Mahler. 2003. Adolescent masculinity, homophobia, and violence: Random school shootings, 1982-2001. American Behavioral Scientist 46: 1439-58. [CrossRef]

Kirby, Aidan. 2007. The London Bombers as "Self-Starters": A case study in indigenous radicalization and the emergence of autonomous cliques. Studies in Conflict $\mathcal{E}$ Terrorism 30: 415-28. [CrossRef]

Kostinsky, Spencer, Edward Bixler, and Paul Kettl. 2001. Threats of School Violence in Pennsylvania After Media Coverage of the Columbine High School Massacre: Examining the Role of Imitation. Archives of Pediatrics E Adolescent Medicine 155: 994-1001. [CrossRef]

Kraemer, Helena, Eric Stice, Alan Kazdin, David Offord, and David Kupfer. 2001. How do risk factors work together? Mediators, moderators, and independent, overlapping, and proxy risk factors. American Journal Psychiatry 158: 848-56. [CrossRef]

Kruglanski, Arie W. 2009. Fully committed: Suicide bombers' motivation and the quest for personal significance. Political Psychology 30: 331-57. [CrossRef]

Kruglanski, Arie W., Jocelyn J. Bélanger, Michele Gelfand, Rohan Gunaratna, Malkanthi Hettiarachchi, Fernando Reinares, Edward Orehek, Jo Sasota, and Keren Sharvit. 2013. Terrorism-a (self) love story: Redirecting the significance quest can end violence. The American Psychologist 68: 559-75. [CrossRef]

Kuznetsov, Sergei A., Anna Yu Karpova, and Aleksei O. Savelev. 2021. Automated detection of ultra-right communities' cross-links in a social network. Vestnik Tomskogo Gosudarstvennogo Universiteta-Filosofiya-Sotsiologiya-Politologiya-Tomsk State University Journal of Philosophy Sociology and Political Science 59: 156-66. [CrossRef] [PubMed]

LaFree, Gary. 2013. Lone-Offender Terrorists. Criminology and Public Policy 12: 59-62. [CrossRef]

Langman, Peter. 2009. Why Kids Kill: Inside the Minds of School Shooters. New York: Palgrave Macmillan.

Langman, Peter. 2015. School Shooters: Understanding High School, College, and Adult Perpetrators. London: Rowman \& Littlefield.

Langman, Peter. 2017. A Bio-Psycho-Social Model of School Shooters. The Journal of Campus Behavioral Intervention 5: 27-34.

Langman, Peter. 2018. Different Types of Role Model Influence and Fame Seeking Among Mass Killers and Copycat Offenders. American Behavioral Scientist 62: 210-28. [CrossRef]

Langman, Peter. 2021. Warning Signs Identifying School Shooters before They Strike. Allentown: Langman Psychological Associates.

Lara-Cabrera, Raúl, Antonio González Pardo, Karim Benouaret, Noura Faci, Djamal Benslimane, and David Camacho. 2017. Measuring the radicalization risk in social networks. IEEE Access 5: 10892-900. [CrossRef]

Larkin, Ralph W. 2009. The Columbine Legacy. Rampage Shootings as Political Acts. American Behavioral Scientist 52: 1309-26. [CrossRef]

Malkki, Leena. 2014. Political Elements in Post-Columbine School Shootings in Europe and North America. Terrorism and Political Violence 26: 185-210. [CrossRef]

McCauley, Clark, and Sophia Moskalenko. 2008. Mechanisms of political radicalisation: Pathways toward terrorism. Terrorism and Political Violence 20: 415-33. [CrossRef] 
McCauley, Clark, and Sophia Moskalenko. 2014. Toward a Profile of Lone Wolf Terrorists: What Moves an Individual from Radical Opinion to Radical Action. Terrorism and Political Violence 26: 69-85. [CrossRef]

McCauley, Clark, and Sophia Moskalenko. 2017. Understanding political radicalization: The two-pyramids model. American Psychologist 72: 205-16. [CrossRef] [PubMed]

Meindl, James N., and Jonathan W. Ivy. 2017. Mass shootings: The role of the media in promoting generalized imitation. American Journal of Public Health 107: 368-70. [CrossRef]

Moghaddam, Fathali M. 2005. The staircase to terrorism: A psychological exploration. American Psychologist 60: 161-69. [CrossRef]

Neumann, Peter R. 2013. The trouble with radicalization. International Affairs 89: 873-93. [CrossRef]

Newman, Katherine S., and Cybelle Fox. 2009. Repeat Tragedy Rampage Shootings in American High School and College Settings, 2002-2008. American Behavioral Scientist 52: 1286-308. [CrossRef]

Newman, Katherine S., Cybelle Fox, Wendy Roth, Jal Mehta, and David Harding. 2004. Rampage: The Social Roots of School Shootings. New York: Basic Books.

Oksanen, Atte, James Hawdon, and Pekka Räsänen. 2014. Glamorizing rampage online: School shooting fan communities on YouTube. Technology in Society 39: 55-67. [CrossRef]

Onnerfors, Andreas, and Kristian Steiner. 2018. Introduction. In Expressions of Radicalization: Global Politics, Processes and Practices. Edited by Kristian Steiner and Andteas Onnerfors. Cambridge: Palgrave Macmillan, pp. 1-38.

Profiles of Individual Radicalization in the United States (PIRUS). 1948-2018. Available online: https: / / www.start.umd.edu/datatools / profiles-individual-radicalization-united-states-pirus (accessed on 8 December 2021).

Rieger, Diana, Lena Frischlich, and Gary Bente. 2020. Dealing with the dark side: The effects of right-wing extremist and Islamist extremist propaganda from a social identity perspective. Media, War E Conflict 13: 280-99. [CrossRef]

Rocque, Michael. 2012. Exploring school rampage shootings: Research, theory, and policy. The Social Science Journal 49: 304-13. [CrossRef]

Sarma, Kiran M. 2017. Risk assessment and the prevention of radicalization from nonviolence into terrorism. American Psychologist 72: 278-88. [CrossRef] [PubMed]

Savelev, Aleksei O., Anna Yu Karpova, Denis V. Chaykovskiy, Alexander D. Vilnin, Anastasia Yu Kaida, Sergei A. Kuznetsov, Lev O. Igumnov, and Nataliya G. Maksimova. 2021. The high-level overview of social media content search engine. IOP Conference Series: Materials Science and Engineering 1019: 012097. [CrossRef]

Schmid, Alex P. 2011. The definition of terrorism. In The Routledge Handbook of Terrorism Research. London: Routledge, pp. 39-98.

School Shooters. n.d. Info Resources on School Shootings, Perpetrators, and Prevention. Available online: https://schoolshooters.info (accessed on 8 December 2021).

Schuurman, Bart, Edwin Bakker, Paul Gill, and Noémie Bouhana. 2017. Lone Actor Terrorist Attack Planning and Preparation: A Data-Driven Analysis. Journal of Forensic Sciences 63: 1191-200. [CrossRef]

Schuurman, Bart, Lasse Lindekilde, Stefan Malthaner, Francis O'Connor, Paul Gill, and Noémie Bouhana. 2019. End of the Lone Wolf: The Typology that Should Not Have Been. Studies in Conflict \& Terrorism 42: 771-78. [CrossRef]

Séguin, Monique, Nadia Chawky, Alain Lesage, Richard Boyer, Stéphane Guay, Pierre Bleau, Paule Miquelon, Nadia Szkrumelak, Warren Steiner, and Denise Roy. 2013. Evaluation of the Dawson College Shooting Psychological Intervention: Moving Toward a Multimodal Extensive Plan. Psychological Trauma-Theory Research Practice and Policy 5: 268-76. [CrossRef]

Silber, Mitchell D., and Arvin Bhatt. 2007. Radicalization in the West: The Homegrown Threat. New York: New York City Police Department. Available online: / / www.brennancenter.org/sites/default/files/legacy/Justice/20090000.Radicalization.in.the. West-Statement.of.Clarification.pdf (accessed on 8 December 2021).

Spaaij, Ramon. 2010. The Enigma of Lone Wolf Terrorism: An Assessment. Studies in Conflict E Terrorism 33: 854-70. [CrossRef]

Stieglitz, Stefan, Milad Mirbabaie, Björn Ross, and Christoph Neuberger. 2018. Social media analytics—Challenges in topic discovery, data collection, and data preparation. International Journal of Information Management 39: 156-68. [CrossRef]

Sureka, Ashish, and Swati Agarwal. 2014. Learning to classify hate and extremism promoting tweets. Paper presented at the Intelligence and Security Informatics Conference (JISIC), Hague, The Netherlands, September 24-26.

Taylor, Max, and John Horgan. 2006. A conceptual framework for understanding psychological process in the development of the terrorist. Terrorism and Political Violence 18: 585-601. [CrossRef]

Taylor, Max, John Horgan, and Marc Sageman. 2015. 'Introduction', Special Issue: Computer-Assisted Terrorism. Dynamics of Asymmetric Conflict 8: 95-96. [CrossRef]

Thompson, Robin L. 2011. Radicalization and the use of social media. Journal of Strategic Security 4: 167-90. [CrossRef]

Towers, Sherry, Andres Gomez-Lievano, Maryam Khan, Anuj Mubayi, and Carlos Castillo-Chavez. 2015. Contagion in Mass Killings and School Shootings. PLoS ONE 10: e0117259. [CrossRef] [PubMed]

Turner, Matthew D. 2011. A Simple Ontology for the Analysis of Terrorist Attacks. Available online: https: / / digitalrepository.unm. edu/ece_rpts / 41 (accessed on 8 December 2021).

Vilnin, Alexander D., Anastasia Yu Kaida, Anna Yu Karpova, Sergei A. Kuznetsov, Nataliya G. Maksimova, Aleksei O. Savelev, and Denis V. Chaykovskiy. 2021. Calendar-correlation analysis of the activity of social network communities. Certificate of State Registration of the Computer Program. Russian Patent 2,021,662,860, August 6. (In Russian)

Weatherby, Georgie A., Sara Strachila, and Bridget McMahon. 2010. School Shootings: The Deadly Result of Teasing and Ostracism? Journal of Criminology and Criminal Research E Education 2: 1-15. 
Wendelberg, Linda. 2021. An Ontological Framework to Facilitate Early Detection of 'Radicalization' (OFEDR)-A Three World Perspective. Journal of Imaging 7: 60. [CrossRef] [PubMed]

Xie, Daniel, Jiejun Xu, and Tsai-Ching Lu. 2016. Automated Classification of Extremist Twitter Accounts Using Content-Based and Network-Based Features. Paper presented at the International Conference on Big Data, Washington, DC, USA, December 5-8. 